\title{
Symmetry training in pigeons can produce functional equivalences
}

\author{
THOMAS R. ZENTALL, TRICIA S. CLEMENT, and JANICE E. WEAVER \\ University of Kentucky, Lexington, Kentucky
}

\begin{abstract}
Functional stimulus equivalence has been demonstrated using a transfer of training design with matching-to-sample training in which two sample stimuli are associated with the same comparison stimulus (A-B, C-B; many-to-one matching). Equivalence is shown by training a new association (A-D) and demonstrating the presence of an emergent relation (C-D). In the present experiment, we show that symmetry training, in which a bidirectional association is trained between two stimuli (A-B, B-A, using successive stimulus presentations followed by reinforcement), can also produce functional equivalence using a transfer of training design (i.e., train B-C, test A-C). The results suggest that training pigeons in the substitutability of two stimuli may be sufficient to produce functional stimulus equivalence between them. The results also have implications for the development of an emergent transitive relation, because training on $\mathrm{A}-\mathrm{B}$ and $\mathrm{B}-\mathrm{C}$ relations results in the emergence of an untrained $\mathrm{A}-\mathrm{C}$ relation, if $\mathrm{B}-\mathrm{A}$ training also is provided.
\end{abstract}

One of the hallmarks of research in animal cognition is the investigation of emergent stimulus relations that develop when stimuli are associated with a common outcome. Investigation of these emergent relations or acquired equivalences has proven to be of considerable theoretical and empirical value (Sidman, 1994). The ability to classify stimuli into appropriate categories based not only on physical similarity but also on sometimes quite abstract meaning is of great importance to humans. For example, exemplars of "tools" are members of the same category because of the way in which they are used.

Sidman and Tailby (1982) defined stimulus equivalence quite specifically in terms of its three formal properties: reflexivity (i.e., identity or sameness; $A=A$ ), symmetry (i.e., bidirectionality or backward associativity; if $\mathrm{A}=\mathrm{B}$, then $\mathrm{B}=\mathrm{A}$ ), and transitivity (i.e., mediated associativity; if $\mathrm{A}=\mathrm{B}$, and $\mathrm{B}=\mathrm{C}$, then $\mathrm{A}=\mathrm{C}$ ). However, less formal definitions of equivalence can be traced to Hull's (1939) proposal "that a stimulus can sometimes evoke a reaction to which it has never been conditioned, i.e., with which it has never been associated" (p. 9). Hull referred to the process by which these mediated associations were acquired as secondary generalization. Such less formal definitions of equivalence, which demonstrate the property of interchangeability of an untrained stimulus with a trained stimulus, have typically been referred to as functional equivalence.

One procedure for demonstrating functional equivalence relations was reported by Urcuioli, Zentall, Jackson-

J.E.W. is now at the Department of Psychology, Ferris State University, Big Rapids, MI. This research was supported by National Institute of Mental Health Grant 59194. Correspondence should be addressed to T. R. Zentall, Department of Psychology, University of Kentucky, Lexington, KY 40506-0044 (e-mail: zentall@ pop.uky.edu).
Smith, and Steirn (1989) with a many-to-one, matchingto-sample procedure. In two-alternative matching-tosample, an initial stimulus (or sample) signals which of two test (or comparison) stimuli is correct. In the manyto-one version of this task, more than one sample signals that a response to a common comparison will be reinforced (A-B, C-B). Thus, for example, red-hue and vertical-line samples may signal that a red-hue comparison is correct, whereas green-hue and horizontal-line samples signal that a green-hue comparison is correct. Demonstration that an emergent relation can develop between samples associated with the same comparison can be shown by training new comparison associations with one pair of the original samples (A-D; e.g., the red sample is now associated with a large circle, and the green sample with a small circle) and then finding that the remaining vertical- and horizontal-line samples are also associated with the large and small circles, respectively (C-D). This phenomenon has been referred to as common coding (Zentall, 1996) or functional equivalence (Astley \& Wasserman, 1996).

Functional equivalence has also been found with the use of a procedure developed by Vaughan (1988). Vaughan first randomly assigned photographs of trees to two arbitrary sets, $\mathrm{A}$ and $\mathrm{B}$. After pigeons had been trained that responses to stimuli in set $A$ were reinforced $(\mathrm{A}+)$ and those to stimuli in set $\mathrm{B}$ were not $(\mathrm{B}-)$, the valence associated with each set was reversed $(\mathrm{A}-\mathrm{B}+)$, and then reversed again $(\mathrm{A}+\mathrm{B}-)$, repeatedly. After a large number of such reversals, Vaughan found that early in a session (i.e., after a small number of stimuli from each set had been presented), the pigeons could respond appropriately to the remaining members of each set (see also Fersen \& Delius, 2000). Thus, these arbitrarily assigned stimuli had become two functional stimulus classes, in spite of the fact that they shared no more in common (in terms of 
their physical similarity or their overall reinforcement histories) than they did with each member of the other class. A similar finding has been reported for sea lions trained with simultaneous discriminations (Kastak, Schusterman, \& Kastak, 2001).

Both of the procedures described for establishing functional equivalences share a common characteristic. In each case, a human might describe the procedures as encouraging subjects to consider two or more stimuli as having the same meaning. In the case of many-to-one matching, samples $\mathrm{A}$ and $\mathrm{C}$ both mean that if $\mathrm{B}$ is chosen it will be reinforced. In the case of multiple reversal training, information about one stimulus (that it is an $\mathrm{S}+$ or an $\mathrm{S}^{-}$) gives the same meaning to all of the other stimuli in the set.

Another procedure that might give common meaning to distinctive stimuli is symmetry training. In symmetry training, subjects learn that when stimulus A appears first, it is always followed by stimulus B and when stimulus B appears first, it is always followed by stimulus A. If this procedure establishes the functional equivalence of $\mathrm{A}$ and $\mathrm{B}$, one should be able to train a new association between one of those stimuli (e.g., A) with a new stimulus, $\mathrm{C}$, and then show that an emergent relation has developed between the remaining stimulus (i.e., B) and the new stimulus $\mathrm{C}$.

There is, in fact, suggestive evidence that symmetry training can result in the establishment of functional equivalences. Yamamoto and Asano (1995) first trained a chimpanzee on a matching task involving A-B relations. Following this training, the subject was tested for the development of symmetrical B-A relations by exchanging samples and comparisons. Although little evidence of emergent symmetry relations was found, this is a fairly typical finding (Hogan \& Zentall, 1977; Lipkens, Kop, Matthijs, 1986; Sidman et al., 1982). Yamamoto and Asano then trained the chimpanzee on the symmetrical $\mathrm{B}-\mathrm{A}$ associations. Following symmetry training, they asked whether training on a new $\mathrm{B}-\mathrm{C}$ association would result in the emergence of a transitive $\mathrm{A}-\mathrm{C}$ association (based on the trained $\mathrm{A}-\mathrm{B}, \mathrm{B}-\mathrm{C}$ associations). They also asked about a possible emergent $\mathrm{C}-\mathrm{A}$ association because Sidman (1990) proposed that positive transfer on a C-A test is evidence of formal stimulus equivalence. Yamamoto and Asano found some evidence of an emergent A-C relation; however, there was no evidence for the emergence of the critical C-A relation. Although the chimpanzee had been trained on the symmetry relation, the authors did not acknowledge the potential role played by symmetry training in the emergence of the $\mathrm{A}-\mathrm{C}$ relation. Thus, it may be that symmetry training results in the development of functional stimulus equivalence because it establishes that the A and B stimuli are interchangeable.

The purpose of the present experiment was to determine whether pigeons that are explicitly trained on symmetrical A-B, B-A relations would show evidence of functional stimulus equivalence using the transfer of training procedure. Thus, if the pigeons were then trained on $\mathrm{B}-\mathrm{C}$ relations, would they show evidence of the development of emergent $\mathrm{A}-\mathrm{C}$ relations?

\section{METHOD}

\section{Subjects}

The subjects were 8 White Carneaux pigeons, purchased as retired breeders (5-8 years old) from the Palmetto Pigeon Plant (Sumter, SC). The pigeons were maintained at $80 \%-85 \%$ of their free-feeding body weights throughout the experiment and were caged individually with grit and water continually available in the home cage. The colony room in which the pigeons were housed was maintained on a 12:12-h, light:dark cycle. All pigeons had previously served in an unrelated study involving simple simultaneous hue discriminations.

\section{Apparatus}

The experiment was conducted in a BRS/LVE (Laurel, MD) sound-attenuating pigeon test chamber. The test chamber measured $30 \mathrm{~cm}$ (from the response panel to the back wall) $\times 36 \mathrm{~cm}$ (across the response panel) $\times 36 \mathrm{~cm}$ (high). Three rectangular response keys ( $2.5 \mathrm{~cm}$ high $\times 3 \mathrm{~cm}$ wide), were separated from each other by $1 \mathrm{~cm}$ and were aligned horizontally on the response panel. Mounted behind the center response key was a 12-stimulus inline projector (Industrial Electronics Engineering, Series 10, Van Nuys, CA, with No. 1820 G.E. lamps) that projected a red hue or a green hue (Kodak Wratten Filter Nos. 26 and 60, respectively), a white line drawn circle (an annulus with 16-mm outside diameter and 13-mm inside diameter), and a white line drawn plus (made up of vertical and horizontal lines $13 \mathrm{~cm}$ long $\times 3 \mathrm{~mm}$ wide). Behind both left and right response keys was a 12-stimulus inline projector that was equipped to project a yellow hue and a blue hue (Kodak Wratten Filter Nos. 9 and 38a, respectively). A houselight (28 V, $0.1 \mathrm{amp}$ ) located at the center of the chamber ceiling provided general illumination. A rear- mounted grain feeder was centered horizontally on the response panel midway between the pecking keys and the floor of the chamber. When operated, the feeder was accessible through a $5.0 \times 5.5 \mathrm{~cm}$ aperture in the response panel. Reinforcement consisted of 1.5 -sec access to Purina Pro Grains. White noise and an exhaust fan mounted on the outside of the chamber masked extraneous noise. The experiment was controlled by a microcomputer located in an adjacent room.

\section{Procedure}

Bidirectional associative training. All pigeons were placed directly on bidirectional associative training in which each trial began with the onset of an initial stimulus on the center key. Ten responses to the initial stimulus extinguished it and presented the second stimulus, also on the center key. Ten responses to the second stimulus resulted in reinforcement. For half of the pigeons red was followed by circle and green was followed by plus, as well as the reverse (i.e., red-circle, circle-red, green-plus, plus-green); for the remaining pigeons, red was followed by plus and green was followed by circle, as well as the reverse (i.e., red-plus, plus-red, green-circle, circlegreen).

In addition, each pigeon was trained on matching-to-sample involving the shape samples (circle and plus) and yellow and blue comparison stimuli. The comparison stimulus defined as correct following each sample was counterbalanced within each group. On matching-to-sample trials, 10 responses were required in order to turn off the sample and immediately turn on the comparison stimuli on the left and right response keys (randomly with respect to location, with the restriction that a particular hue could not occur on the same side key for more than three consecutive trials). In the presence of the comparison stimuli, one response to either side key 
constituted a choice and turned off the comparison stimuli. If a response was made to the comparison designated as correct, reinforcement was made available for the first $1.5 \mathrm{sec}$ of the 10 -sec intertrial interval (ITI). If a response was made to the comparison designated as incorrect, only the ITI was initiated. The houselight was illuminate during the ITI. Each session consisted of 96 trials, 48 successive stimulus-stimulus trials (12 trials with each of the four pairings of the stimuli) and 48 matching-to-sample trials (24 trials with each sample). Sessions were conducted 6 days a week. Training continued for 20 sessions beyond a criterion of $90 \%$ correct or higher matching accuracy for each sample.

Testing. One 96-trial test session was conducted on the day following the last training session. On half of the trials during testing, pigeons received the same successive stimulus-stimulus presentations experienced in training (e.g., red-circle, circle-red, green-plus, plus-green). The remaining test trials were matching-to-sample and hue samples replaced the shape samples used during training. The comparison stimuli remained yellow and blue. For half of the pigeons, the comparison designated as correct with each sample was consistent with the presumed substitutability of the successive stimulusstimulus pairings established in training (consistent group); for the remaining pigeons (inconsistent group), those contingencies were reversed. The design of the experiment appears in Figure 1.

\section{RESULTS}

\section{Training}

The pigeons acquired the matching-to-sample portion of training (to the criterion of two successive sessions at $90 \%$ correct or better) in an average of 45.2 sessions. Mean sessions to criterion for pigeons assigned to the consistent and inconsistent groups were 41.0 and 49.5, respectively (see Table 1). When the acquisition scores were subjected to a one-way analysis of variance (ANOVA) with test group (consistent vs. inconsistent) as the factor, it indicated that the effect of group was not significant $(F<1)$. In all of the analyses, the .05 level of statistical significance was adopted.

\section{Testing}

On test trials, when hue samples were substituted for the shape samples, differences in matching transfer were found for the two groups. Overall, pigeons in the consistent group transferred at $62.0 \%$, whereas pigeons in the inconsistent group transferred at $39.5 \%$ (see Table 1). A one-

\begin{tabular}{|c|c|c|}
\hline \multicolumn{3}{|l|}{ Training: } \\
\hline \multicolumn{2}{|c|}{ Successive Presentations } & \multirow{3}{*}{$\begin{array}{l}\text { Matching-to-Sample } \\
\text { Circle - Yellow (Blue) } \\
\text { Plus - Blue (Yellow) }\end{array}$} \\
\hline Red - Circle & Circle - Red & \\
\hline Green - Plus & Plus - Green & \\
\hline \multicolumn{3}{|l|}{ Test: } \\
\hline \multicolumn{3}{|c|}{ Matching-to-Sample } \\
\hline \multicolumn{2}{|c|}{ Consistent Group } & Inconsistent Group \\
\hline \multirow{2}{*}{\multicolumn{2}{|c|}{$\begin{array}{l}\text { Red - Yellow (Blue) } \\
\text { Green - Blue (Yellow) }\end{array}$}} & Red - Blue (Yellow) \\
\hline & & Green - Yellow (Blue) \\
\hline
\end{tabular}

Figure 1. Design of the experiment. All successive presentations were followed by food. For matching-to-sample training, the first stimulus represents the sample, and the second stimulus, the correct comparison. The incorrect comparison is presented in parentheses. Stimuli shown represent only one of the four counterbalancing conditions.
Table 1

Data from Individual Pigeons

\begin{tabular}{cccc}
\hline \multicolumn{2}{c}{ Consistent Group } & & \multicolumn{2}{c}{ Inconsistent Group } \\
\cline { 1 - 1 } Pigeon No. & $\begin{array}{c}\text { Sessions } \\
\text { to Criterion }\end{array}$ & Pigeon No. & $\begin{array}{c}\text { Sessions } \\
\text { to Criterion }\end{array}$ \\
\hline \multicolumn{3}{c}{ Acquisition } \\
5150 & 63 & 5175 & 64 \\
6678 & 53 & 6631 & 44 \\
9637 & 22 & 4312 & 20 \\
6613 & 26 & 4964 & 70 \\
Mean & 41.0 & & 49.5 \\
& & Transfer & \\
5150 & $58.3 \%$ & 5175 & $50.0 \%$ \\
6678 & $75.0 \%$ & 6631 & $33.3 \%$ \\
9637 & $62.5 \%$ & 4312 & $50.0 \%$ \\
6613 & $52.1 \%$ & 4964 & $25.0 \%$ \\
Mean & $61.98 \%$ & & $39.58 \%$ \\
\hline
\end{tabular}

way ANOVA (with group as the factor) applied to these data indicated that the group difference in matching accuracy on the test session was significant $[F(1,8)=8.04]$.

\section{DISCUSSION}

The present results suggest that pigeons given symmetry training $(\mathrm{A}-\mathrm{B}, \mathrm{B}-\mathrm{A})$ involving the successive presentation of stimuli followed by reinforcement can develop functional equivalences between those stimuli, as indicated by a transfer-of-training test. Specifically, when new $\mathrm{B}-\mathrm{C}$ associations were trained with the matchingto-sample procedure, emergent A-C relations were found. We suggest that such symmetry training can produce functional equivalence by establishing that the $\mathrm{A}$ and $\mathrm{B}$ stimuli are interchangeable (in this case, initial presentation of each stimulus predicts the other). Although technically the term equivalence implies that evidence for complete transfer has been found (i.e., matching accuracy on the transfer test that is similar to that found at the end of training), researchers have generally interpreted results indicating that there is a significant difference in matching accuracy between consistent and inconsistent transfer groups as evidence of functional equivalence (Urcuioli et al., 1989; Zentall, 1998).

A unique aspect of the present experiment is that symmetry training involved the successive presentation of two stimuli followed by reinforcement rather than the more typical matching-to-sample procedure. The reason why we did not use matching-to-sample for symmetry training is that there is evidence that when samples and comparisons exchange places (as in A-B and B-A training) and they no longer appear in the same locations, they are no longer treated as the same stimuli (Lionello \& Urcuioli, 1998). Thus, the procedure used in the present experiment may prove to be useful in future functional equivalence research.

\section{Implications of Functional Equivalence}

The demonstration of functional equivalence in animals has important implications for theories of learning 
by animals. The human ability to use a word to symbolically represent an object (semantics) requires that the word and the object become functionally equivalent. Although the word and object are quite different in form, the word can substitute for the object in the context of communication. If animals such as pigeons are capable of forming stimulus sets that are not based on their physical similarity, this suggests that they are capable of the kind of symbolic representation that humans have exploited so well in their use of language. In fact, Sidman and Cresson (1973) viewed functional equivalence training as a potential means of overcoming the language deficits of developmentally delayed humans.

\section{Evidence of Transitivity?}

Although their chimpanzee did not show evidence of stimulus equivalence as defined by $\mathrm{C}-\mathrm{A}$ transfer (Sidman, 1990), Yamamoto and Asano (1995) concluded that she did show evidence of functional equivalence in the form of a emergent transitive relation. That is, following A-B, B-C training, they found evidence of A-C transfer.

In general, however, transitivity has been difficult to demonstrate in animals. Steirn, Jackson-Smith, and Zentall (1991) attempted to demonstrate transitivity in pigeons by first training them to associate a red hue with food and a green hue with no food $(\mathrm{A}-\mathrm{B})$. They then trained the pigeons with matching-to-sample in which food and the absence of food were samples and the comparison stimuli were vertical and horizontal lines (B-C). On test trials, the red and green stimuli were substituted for the food and no-food samples and were presented with the line-orientation comparison stimuli (A-C). The positive transfer found was quite modest, but it was significant. Unfortunately, Steirn et al.'s results may be explained in terms of overt response mediation. That is, during original training with the red and green hues $(\mathrm{A}-\mathrm{B})$, the pigeons learned to peck at the red hue that was followed by food and to refrain from pecking the green hue that was not. During interim training $(\mathrm{B}-\mathrm{C})$, the pigeons pecked at the food when it was the sample and refrained from pecking when it was not. Thus, a common pecking (and absence-of-pecking) response to the A and B stimuli may have mediated the transfer on test trials.

In our laboratory, we have repeatedly attempted to test for emergent transitivity by using stimuli more neutral than the biologically important food versus absence-offood stimuli used by Steirn et al. (1991), but in no case have we been successful in obtaining significant evidence for transitivity in pigeons. One reason for the failure to find associative transitivity using this task with pigeons is that for positive transfer to occur, it may be necessary for the initial stimuli from original training (A) to be substitutable for the samples from interim training (B), and A-B training appears not to result in such substitutability. Yamamoto and Asano (1995) may have (inadvertently) trained their subject to consider the $\mathrm{A}$ and $\mathrm{B}$ stimuli to be interchangeable by including $\mathrm{B}-\mathrm{A}$ training trials prior to $\mathrm{B}-\mathrm{C}$ training and $\mathrm{A}-\mathrm{C}$ test. It is quite likely that the addition of $\mathrm{B}-\mathrm{A}$ training allowed for the development of an emergent equivalence relation unrelated to transitivity. The fact that the procedure for testing for transitivity following symmetry training is exactly the same as the test for functional equivalence following symmetry training should be given more attention by those studying transitivity in animals.

Schusterman and Kastak (1993) have shown evidence of an emergent transitive relation in a sea lion, but they provided a substantial number of reinforced tests of symmetry prior to the transitivity test. Whether these symmetry tests were responsible for the finding of transitivity is not clear. However, this sea lion clearly had evidenced a high level of symmetry performance prior to the transitivity test.

A further indication of the important of symmetry training (or, for some species, the demonstration of emergent symmetric relations; see Schusterman \& Kastak, 1993) is the general failure to find functional equivalence using the one-to-many matching-to-sample design (Urcuioli \& Zentall, 1993; Urcuioli, Zentall, \& DeMarse, 1995). In this case, over the course of training, each sample stimulus is associated with two different comparison stimuli (i.e., $\mathrm{A}-\mathrm{B}, \mathrm{A}-\mathrm{C}$ ). If one of these comparisons is then associated with a new sample (D-B), little evidence has been found for the development of an emergent $\mathrm{D}-\mathrm{C}$ relation.

In the present experiment, one could view original training as involving the acquisition of $\mathrm{B}-\mathrm{A}$ and $\mathrm{B}-\mathrm{C}$ associations (i.e., one-to-many training) with added A-B training (symmetry). Thus test for an emergent A-C relation directly demonstrates the development of functional equivalence following one-to-many training.

It is interesting that functional equivalence can be demonstrated in pigeons in the absence of symmetry training when training involves many-to-one matching (see, e.g., Urcuioli et al., 1989). Why there is such a difference between many-to-one training and one-to-many training is not clear, but it may have something to do with the relative temporal direction of the common associates. Perhaps it is easier to recognize the equivalence of two events when they have the same meaning in the forward direction (i.e., $\mathrm{A}$ and $\mathrm{C}$ both mean "respond to B") as opposed to the backward direction (i.e., A means "respond to both B and C").

Whatever the reason for this difference in functional equivalence relations established following many-to-one and one-to-many training, symmetry training appears to facilitate the development of such emergent relations. Thus, symmetry training may provide a useful general tool for the establishment of stimulus classes in nonhuman organisms.

\section{REFERENCES}

Ast ley, S. L., \& Wasserman, E. A. (1996). Mediating associations, essentials, and nonsimilarity-based categorization. In T. R. Zentall \& P. M. Smeets (Eds.), Stimulus class formation in humans and animals (pp. 111-133). Amsterdam: Elsevier, North-Holland. 
Fersen, L. von, \& Delius, J. D. (2000). Acquired equivalences between auditory stimuli in dolphins (Tursiops truncatus). Animal Cognition, 3, 79-83.

Hogan, D. E., \& Zentall, T. R. (1977). Backward associative learning in the pigeon. American Journal of Psychology, 90, 3-15.

Hull, C. L. (1939). The problem of stimulus equivalence in behavior theory. Psychological Review, 46, 9-30.

Kastak, C. R, Schusterman, R. J., \& Kastak, D. (2001). Equivalence classification by California sea lions using class-specific reinforcers. Journal of the Experimental Analysis of Behavior, 76, 131-158.

Lionello, K. M., \& UrCUioli, P. J. (1998). Control by sample location in pigeons' matching to sample. Journal of the Experimental Analysis of Behavior, 70, 235-251.

Lipkens, R., Kop, P. F., \& Matthiss, W. (1986). A test of symmetry and transitivity in the conditional discrimination performances of pigeons. Journal of the Experimental Analysis of Behavior, 49, 395-409.

Schusterman, R. J., \& KastaK, D. (1993). A California sea lion (Zalophus californianus) is capable of forming equivalence relations. Psychological Record, 43, 823-839.

Sidman, M. (1990). Equivalence relations: Where do they come from? In H. Lejeune \& D. Blackman (Eds.), Behavior analysis in theory and practice: Contributions and controversies (pp. 93-114). Hillsdale, NJ: Erlbaum.

SIDMAN, M. (1994). Equivalence relations and behavior: A research story. Boston: Authors Cooperative.

Sidman, M., \& Cresson, O. (1973). Reading and crossmodal transfer of stimulus equivalences in severe retardation. American Journal of Mental Deficiency, 77, 515-523.

Sidman, M., Rauzin, R, Lazar, R., Cunningham, S., Tailby, W., \& CARrigan, P. (1982). A search for symmetry in the conditional discrimination of rhesus monkeys, baboons, and children. Journal of the Experimental Analysis of Behavior, 37, 23-44.

Sidman, M., \& Tailby, W. (1982). Conditional discrimination vs. matching-to-sample: An expansion of the testing program. Journal of the Experimental Analysis of Behavior, 37, 5-22.

Steirn, J. N., JaCKSON-Smith, P., \& Zentall, T. R. (1991). Mediational use of internal representations of food and no-food events by pigeons. Learning \& Motivation, 22, 353-365.

Urcuioli, P. J., \& Zentall, T. R. (1993). A test of comparison-stimulus substitutability following one-to-many matching by pigeons. Psychological Record, 43, 725-744.

Urcuioli, P. J., Zentall, T. R., \& DeMarse, T. (1995). Transfer to derived sample-comparison relations by pigeons following many-toone versus one-to-many matching with identical training relations. Quarterly Journal of Experimental Psychology, 48B, 158-178.

Urcuioli, P. J., Zentall, T. R., Jackson-Smith, P., \& Steirn, J. N. (1989). Evidence for common coding in many-to-one matching: Retention, intertrial interference, and transfer. Journal of Experimental Psychology: Animal Behavior Processes, 15, 264-273.

VAughan, W., JR. (1988). Formation of equivalence sets in pigeons. Journal of Experimental Psychology: Animal Behavior Processes, 14, 36-42.

Yamamoto, J., \& Asano, T. (1995). Stimulus equivalence in a chimpanzee (Pan troglodytes). Psychological Record, 45, 3-21.

ZENTALL, T. R. (1996). An analysis of stimulus class formation in animals. In T. R. Zentall \& P. M. Smeets (Eds.), Stimulus class formation in humans and animals (pp.15-34). Amsterdam: Elsevier, NorthHolland.

ZENTALL, T. R. (1998). Symbolic representation in animals: Emergent stimulus relations in conditional discrimination learning. Animal Learning \& Behavior, 26, 363-377.

(Manuscript received November 6, 2001; revision accepted for publication April 29, 2002.) 